\title{
Stability of the intra- operative arterial to end-tidal carbon dioxide partial pressure difference in children with congenital heart disease
}

The purpose of this study was to evaluate the stability of the arterial $\mathrm{PCO}_{2}\left(\mathrm{PaCO}_{2}\right)$ to end-tidal $\mathrm{PCO}_{2}\left(\mathrm{PETCO}_{2}\right)$ partial pressure difference $\left(\mathrm{Pa}-\mathrm{ETCO} \mathrm{C}_{2}\right)$ during surgery using $\mathrm{PETCO}_{2}$ monitoring, in children with congenital heart disease (CHD). Forty children with $C H D$ were studied: ten children with no interchamber communication and normal pulmonary blood flow (PBF) (normal group); ten acyanotic children with increased PBF (acyanotic-shunting group); ten cyanotic children with mixing type lesions and normal or increased PBF (mixing group), and ten cyanotic children with right-to-left intracardiac shunts demonstrating decreased and variable PBF (cyanoticshunting group). Simultaneous $\mathrm{PaCO}_{2}$ recordings and $\mathrm{PETCO}_{2}$ measurements were obtained for each patient during five intraoperative events: (1) control time, arterial line placement under anaesthesia; (2) time 1, patient preparation; (3) time 2, immediately after sternotomy; (4) time 3, after heparin administration; and (5) time 4, immediately after aortic cannulation. Initially, cyanotic children demonstrated a greater $\mathrm{Pa}-\mathrm{ETCO}_{2}$ compared with acyanotic children $(P<0.05)$. There was no difference in the Pa-ETCO $\mathrm{O}_{2}$ over time in the control, acyanotic-

\section{Key words}

ANAESTHESIA: cardiovascular, paediatric;

CARBON DIOXIDE: tension, end-tidal gradiant;

HEART: congenital defects;

MEASUREMENT TECHNIQUES: capnometry.

From the Departments of Anaesthesia, Paediatrics (Cardiology) and The Research Institute, The Hospital for Sick Children and the University of Toronto, Toronto, Ontario, Canada.

Address correspondence to: Dr. Frederick A. Burrows, The Department of Anaesthesia, The Hospital for Sick Children, 555 University Avenue, Toronto, Ontario, Canada M5G 1 X8.

Accepted for publication 17th May, 1991. shunting, or mixing groups. The Pa-ETCO $\mathrm{O}_{2}$ in the children with cyanotic-shunting lesions at times 2 and 3 was greater $(P<$ 0.05) than at their control times. We conclude that the $\mathrm{Pa}-\mathrm{ETCO} \mathrm{O}_{2}$ of children with acyanotic-shunting and mixing congenital heart lesions is stable intraoperatively, although patients with mixing congenital heart lesions may demonstrate large individual variations. In children with cyanotic-shunting congenital heart lesions, the $\mathrm{Pa}-\mathrm{ETCO}_{2}$ is not stable. The $\mathrm{PETCO}_{2}$ cannot be used during surgery to estimate reliably the $\mathrm{PaCO}_{2}$ in children with cyanotic $\mathrm{CHD}$.

Nous avons voulu par cette étude, évaluer la stabilité du gradient entre la $\mathrm{PCO}_{2}$ artérielle $\left(\mathrm{PaCO}_{2}\right)$ et la $\mathrm{PCO}_{2}$ en fin d'expiration $\left(\mathrm{PETCO}_{2}\right)$ chez quatre groupes d'enfants atteints $d$ ' une maladie cardiaque congénitale. Dix enfants $n$ 'avaient pas de communication intercavitaire et leur débit sanguin pulmonaire (DSP) était normal (groupe normal); dix avaient un DSP augmenté sans cyanose (groupe shunt acyanotique); dix avaient un DSP normal ou augmenté avec mélange des circulations (groupe mélange) et dix autres avaient un shunt intracardiaque droit-gauche avec cyanose et leur DSP était diminué et variable (groupe shunt cyanotique). On a noté simultanément la $\mathrm{PaCO}_{2}$ et la PETCO $\mathrm{O}_{2}$ à cinq occasions: 1) lors de l'insertion de la canule artérielle, 2) pendant la préparation chirurgicale, 3) juste après la sternotomie, 4) après l'injection de l' héparine et 5) juste après la canulation aortique. Au départ, les enfants cyanotiques avaient un gradient $\mathrm{Pa}-\mathrm{ETCO}_{2}$ plus grand que les autres enfants $(P<0,05)$. Le gradient restait stable lors des cinq périodes de mesure chez les enfants des groupes normaux, shunt acyanotique et mélange. Par contre le gradient était plus grand après la sternotomie et après l' injection d' héparine qu' au départ chez les enfants du groupe shunt cyanotique. En conclusion, le gradient $\mathrm{Pa}-\mathrm{ETCO}_{2}$ ne change pas pendant une opération chez les enfants qui ont un shunt sans cyanose et chez ceux affligés d'un mélange des circulations quoique les variations individuelles peuvent étre assez grandes chez ces derniers. 
Par contre, les enfants atteints d'une maladie cardiaque congénitale avec shunt et cyanose ont un gradient $\mathrm{Pa}-\mathrm{ETCO}$ imprévisible qui rend impossible l'utilisation peropératoire de la $\mathrm{PETCO}_{2}$ en vue d'estimer la $\mathrm{PaCO}_{2}$.

Previous studies have shown that the end-tidal partial pressure of carbon dioxide $\left(\mathrm{PeTCO}_{2}\right)$ approximates the arterial carbon dioxide tension $\left(\mathrm{PaCO}_{2}\right)$ in children without cardiopulmonary disease. ${ }^{1-6}$ However, the $\mathrm{PETCO}_{2}$ underestimates the $\mathrm{PaCO}_{2}$ in children with certain congenital heart defects, which results in a $\mathrm{PaCO}_{2}$-to$\mathrm{PETCO}_{2}$ difference $\left.(\mathrm{Pa}-\mathrm{ETCO})_{2}\right)^{3,7,8}$ In these studies of children with congenital heart disease (CHD), $\mathrm{Pa}-\mathrm{ETCO}_{2}$ determinations were made during haemodynamically stable conditions at only one time: therefore the predictability of the $\mathrm{Pa}-\mathrm{ETCO}_{2}$ during surgical stimulation has not been examined. The $\mathrm{Pa}-\mathrm{ETCO}_{2}$ is influenced by abnormalities in physiological dead space and venous admixture. ${ }^{3,9}$ In children with certain congenital cardiac defects, intraoperative manipulations may acutely alter the physiological dead space and venous admixture by altering pulmonary blood flow (PBF) ${ }^{3,6,9}$ However, not all congenital cardiac lesions are subject to acute alterations in PBF: the $\mathrm{Pa}-\mathrm{ETCO}_{2}$ may therefore be constant in these lesions intraoperatively. The purpose of this study was to evaluate clinically the stability of the $\mathrm{Pa}-\mathrm{ETCO}_{2}$ during surgery in children with various forms of CHD.

\section{Methods}

After obtaining approval from the Human Subjects Review Committee of The Hospital for Sick Children, Toronto, Ontario, and informed parental consent, we studied 40 infants and children older than one year and weighing more than $6 \mathrm{~kg}$. All children were ASA physical status II-III and scheduled for corrective or palliative cardiac surgery. Patients with pre-existing pulmonary disease or congestive heart failure and patients with existing arterial to pulmonary palliative shunts were excluded from the study.

The patients were categorized into four groups according to their preoperative cardiological diagnosis, determined from physical, echocardiographic, oximetric, and/ or angiographic examinations, and were subsequently classified on the basis of their PBF (Table): ten patients with no intracardiac communication and normal PBF (normal group); ten acyanotic patients with increased PBF because of left-to-right intracardiac shunting of blood (acyanotic-shunting group); ten cyanotic patients with normal or increased PBF (mixing group); and ten cyanotic patients with right-to-left intracardiac shunting of blood with decreased PBF (cyanotic-shunting group). The first three groups of patients, who were not subject to hypercyanotic episodes, were diagnosed as having stable PBF. The fourth group (cyanotic-shunting group) had tetralogy of Fallot and variable PBF, demonstrated by a history of hypercyanotic episodes.

Anaesthesia was induced with intravenous fentanyl $\left(35-70 \mu \mathrm{g} \cdot \mathrm{kg}^{-1}\right)$ and diazepam $\left(0.25 \mathrm{mg} \cdot \mathrm{kg}^{-1}\right)$. After paralysis with pancuronium $\left(0.15 \mathrm{mg} \cdot \mathrm{kg}^{-1}\right)$, the trachea was intubated with an oral/nasal tube. The size of the tube was selected such that no audible air leak was present below $35 \mathrm{~cm} \mathrm{H}_{2} \mathrm{O}$ peak inspiratory pressure. The lungs were mechanically ventilated with an air/oxygen mixture with an Air-Shields Ventimeter ventilator (Air-Shields/ Vickers, Hatboro, PA) with an Ayre's t-piece breathing circuit (Jackson-Rees modification). Fresh gas flow, tidal volume, peak inspiratory pressure, and respiratory rate were adjusted to maintain the $\mathrm{PaCO}_{2}$ within the range of 30 to $42 \mathrm{mmHg}$. Positive end-expiratory pressure of 3.0 cm $\mathrm{H}_{2} \mathrm{O}$ was applied to the lungs. Anaesthesia was maintained with fentanyl and pancuronium. Normothermia (rectal temperature $>36.5^{\circ} \mathrm{C}$ ) was maintained with a Blanketrol II warming blanket (Cincinnati Sub-Zero Products, Inc., Cincinnati, $\mathrm{OH}$ ) and a Dual-Servo Heated Respiratory Humidifier (Fisher \& Paykel Ltd., Aukland, New Zealand).

Patients were studied in the supine horizontal position after induction of anaesthesia and intubation. Distal $\mathrm{PETCO}_{2}$ was sampled continuously at a flow rate of 150 $\mathrm{ml} \cdot \mathrm{min}^{-1}$ with a Puritan-Bennett/Datex Model 253 infrared analyzer (Datex Instrumentarium Corp., Helsinki, Finland) calibrated with dry 5.17 per cent $\mathrm{CO}_{2}$ before each use. The gas was sampled through a 16 standardwire gauge Deseret Intracath (Becton Dickinson Deseret Medical, Sandy, UT). The catheter was inserted through a Luer-Lok connection in the elbow (12800, Dryden Corporation, Indianapolis, IN) to within $5 \mathrm{~mm}$ of the distal end of the tracheal tube. The hub of the catheter was secured to the Luer-Lok connector of the sampling tube.

Simultaneous $\mathrm{PaCO}_{2}$ measurements and $\mathrm{PETCO}_{2}$ recordings were taken at five points: (1) control time, after placement of the arterial line under anaesthesia, while the patient was haemodynamically stable and before stimulation; (2) time 1, during preparation of patient: (3) time 2, immediately after sternotomy; (4) time 3 , four minutes after administration of heparin; and (5) time 4, immediately after placement of aortic cannula but before the institution of cardiopulmonary bypass. All $\mathrm{PETCO}_{2}$ values were obtained from alveolar $\mathrm{PCO}_{2}$ tracings demononstrating flat alveolar plateaus. These times were chosen to maximize the effects of stimulation and thus potentially exaggerate the $\mathrm{Pa}-\mathrm{ETCO} \mathrm{C}_{2}$.

\section{Data analysis}

A one-way analysis of variance (ANOVA) was used to 
TABLE Demographic data

\begin{tabular}{|c|c|c|c|c|c|c|}
\hline \multirow[b]{2}{*}{ Group } & \multirow[b]{2}{*}{$\begin{array}{l}\text { Patient } \\
\text { no. }\end{array}$} & \multirow[b]{2}{*}{$\begin{array}{l}\text { Age } \\
(y r)\end{array}$} & \multirow[b]{2}{*}{$\begin{array}{l}\text { Weight } \\
(\mathrm{kg})\end{array}$} & \multirow[b]{2}{*}{ Diagnosis } & \multicolumn{2}{|l|}{ Control } \\
\hline & & & & & $\begin{array}{l}\mathrm{PETCO}_{2} \\
(\mathrm{mmHg})\end{array}$ & $\begin{array}{l}\mathrm{Pa}-\mathrm{ETCO}_{2} \\
(\mathrm{mmHg})\end{array}$ \\
\hline \multirow[t]{10}{*}{ Normal } & 1 & 2.5 & 10.4 & Aortic stenosis & 32 & 0.3 \\
\hline & 2 & 8.0 & 18.9 & Aortic stenosis & 31 & 1.1 \\
\hline & 3 & 1.0 & 11.1 & Aortic stenosis & 29 & 1.5 \\
\hline & 4 & 1.5 & 13.2 & Aortic stenosis & 33 & 0.6 \\
\hline & 5 & 12.0 & 28.6 & Anomalous LCA & 37 & -0.3 \\
\hline & 6 & 7.5 & 15.7 & WPW & 38 & 0.5 \\
\hline & 7 & 1.0 & 10.9 & PI & 35 & 0.3 \\
\hline & 8 & 11.0 & 27.4 & Subaortic ridge & 31 & 1.7 \\
\hline & 9 & 8.5 & 17.3 & Aortic stenosis & 29 & 0.8 \\
\hline & 10 & 13.0 & 38.0 & WPW & 31 & 0.9 \\
\hline Mean ( $( \pm \mathrm{SD})$ & & $6.6 \pm 4.7$ & $19.2 \pm 9.3$ & & $32.6 \pm 3.1$ & $0.7 \pm 0.6$ \\
\hline \multirow[t]{10}{*}{ Acyanotic shunting } & 1 & 2.5 & 12.2 & VSD & 35 & 1.1 \\
\hline & 2 & 1.5 & 10.0 & VSD & 29 & 2.8 \\
\hline & 3 & 2.0 & 8.4 & ASD & 34 & 0.5 \\
\hline & 4 & 1.0 & 7.7 & VSD & 27 & 0.4 \\
\hline & 5 & 3.0 & 15.7 & VSD & 31 & 2.0 \\
\hline & 6 & 4.5 & 16.9 & ASD & 38 & 0.2 \\
\hline & 7 & 14.0 & 42.2 & VSD & 34 & 1.1 \\
\hline & 8 & 13.5 & 50.1 & ASD & 48 & -0.9 \\
\hline & 9 & 5.0 & 12.3 & ASD & 30 & 0.6 \\
\hline & 10 & 1.5 & 10.0 & VSD & 29 & 1.0 \\
\hline Mean $( \pm S D)$ & & $4.9 \pm 4.8$ & $18.7 \pm 14.9$ & & $33.5 \pm 6.1$ & $0.9 \pm 1.0$ \\
\hline \multirow[t]{10}{*}{ Cyanotic shunting } & 1 & 5.0 & 15.3 & ToF & 29 & 2.7 \\
\hline & 2 & 5.0 & 18.3 & ToF & 24 & 14.9 \\
\hline & 3 & 1.5 & 12.9 & ToF & 36 & 4.0 \\
\hline & 4 & 7.0 & 13.6 & ToF & 30 & 8.9 \\
\hline & 5 & 1.0 & 6.8 & ToF & 29 & 4.6 \\
\hline & 6 & 2.5 & 11.9 & ToF & 30 & 0.9 \\
\hline & 7 & 2.0 & 12.9 & ToF & 39 & 0.0 \\
\hline & 8 & 2.0 & 11.3 & ToF & 34 & -1.9 \\
\hline & 9 & 2.5 & 14.0 & ToF & 32 & 3.5 \\
\hline & 10 & 5.0 & 17.9 & ToF & 31 & 3.0 \\
\hline Męan ( \pm SD) & & $3.4 \pm 2.0$ & $13.5 \pm 3.3$ & & $31.4 \pm 4.2$ & $4.1 \pm 4.8^{*}$ \\
\hline \multirow[t]{10}{*}{ Mixing } & 1 & 3.0 & 15.6 & $\mathrm{UH}$ & 34 & 5.1 \\
\hline & 2 & 1.5 & 9.3 & DORV & 26 & 5.1 \\
\hline & 3 & 8.5 & 25.0 & UH & 29 & 4.3 \\
\hline & 4 & 4.5 & 14.9 & DORV & 33 & 4.5 \\
\hline & 5 & 9.5 & 31.0 & $\mathrm{UH}$ & 37 & 4.8 \\
\hline & 6 & 8.0 & 19.4 & DORV & 32 & 12.3 \\
\hline & 7 & 4.5 & 14.7 & DORV & 29 & 1.1 \\
\hline & 8 & 4.5 & 13.3 & TGA/VSD & 30 & 4.9 \\
\hline & 9 & 3.0 & 14.6 & UH & 30 & 9.1 \\
\hline & 10 & 3.5 & 13.8 & UH & 27 & 0.8 \\
\hline Mean $( \pm S D)$ & & $5.0 \pm 2.7$ & $17.2 \pm 6.4$ & & $30.7 \pm 3.3$ & $5.2 \pm 3.4^{*}$ \\
\hline
\end{tabular}

LCA = left coronary artery; WPW = Wolf-Parkinson-White syndrome; PI = pulmonary insufficiency; VSD = ventricular septal defect; $\mathrm{ASD}=$ atrial septal defect; ToF $=$ tetralogy of Fallet; $\mathrm{UH}=$ univentricular heart; DORV $=$ double-outlet right ventricle; $\mathrm{TGA}=$ transposition of the great arteries.

$* P<0.05$ compared with the acyanotic groups. 
compare the demographic data, control $\mathrm{PETCO}_{2}$, and control Pa-ETCO $\mathrm{CO}_{2}$; two-way ANOVA, to determine the effect of the type of cardiac lesion and the sample time on the $\mathrm{Pa}-\mathrm{ETCO}_{2}$. The Tukey test was used for multiple comparisons.

Data were examined to determine the proportion of clinically relevant alterations in the $\mathrm{Pa}-\mathrm{ETCO}_{2}$ in each group. A clinically relevant alteration was accepted as an increase or decrease in the $\mathrm{Pa}-\mathrm{ETCO}$ of greater than 5 $\mathrm{mmHg}$ from the control value in an individual patient. Between group comparisons were made with the Fisher exact test.

Statistical significance was accepted as $P<0.05$. Bonferroni correction for multiple comparisons was used where applicable.

\section{Results}

The demographic data are presented in the Table. There were no differences in the age, weight, or control $\mathrm{PETCO}_{2}$ among the four groups of patients. The control Pa-ETCO values of the two acyanotic groups were less than those for the two cyanotic groups $(P<0.05)$, but there was no difference between the two acyanotic groups nor between the two cyanotic groups.

The mean ( $\pm S D$ ) duration of the study, $43 \pm 18 \mathrm{~min}$, was similar among the four groups. The individual $\mathrm{Pa}-\mathrm{ETCO}_{2}$ in $\mathrm{mmHg}$ at the five sample times are presented in Figure 1. The mean $( \pm \mathrm{SD}) \mathrm{Pa}-\mathrm{ETCO}_{2}$ of the four groups during the five sampling times is depicted in Figure 2. The Pa-ETCO $\mathrm{CO}_{2}$ was affected both by the type of congenital cardiac lesion and by the sample time. At all five sample times, the Pa-ETCO $\mathrm{CO}_{2}$ was less $(P<0.05)$ for the two acyanotic groups than for the two cyanotic groups, but there was no difference between the two acyanotic groups or between the two cyanotic groups of patients. The Pa-ETCO ${ }_{2}$ for the normal, acyanoticshunting or mixing groups did not differ from that for the control group during the five sample times. In contrast, a difference $(P<0.05)$ in the Pa-ETCO ${ }_{2}$ for the cyanoticshunting group occurred at sample times 3 and 4 (after administration of heparin and after placement of aortic cannula) compared with control (placement of the arterial line).

For the normal and the acyanotic-shunting groups of patients, there were no clinically relevant differences in Pa-ETCO ${ }_{2}$ during any of the five sampling times (Figure 1). The proportions of patients demonstrating clinically relevant alterations in the $\mathrm{Pa}-\mathrm{ETCO}_{2}$ in the cyanoticshunting and the mixing groups of patients were equal (five of ten patients) and were greater $(P<0.05)$ than the normal and the acyanotic-shunting groups $(0$ of ten patients).

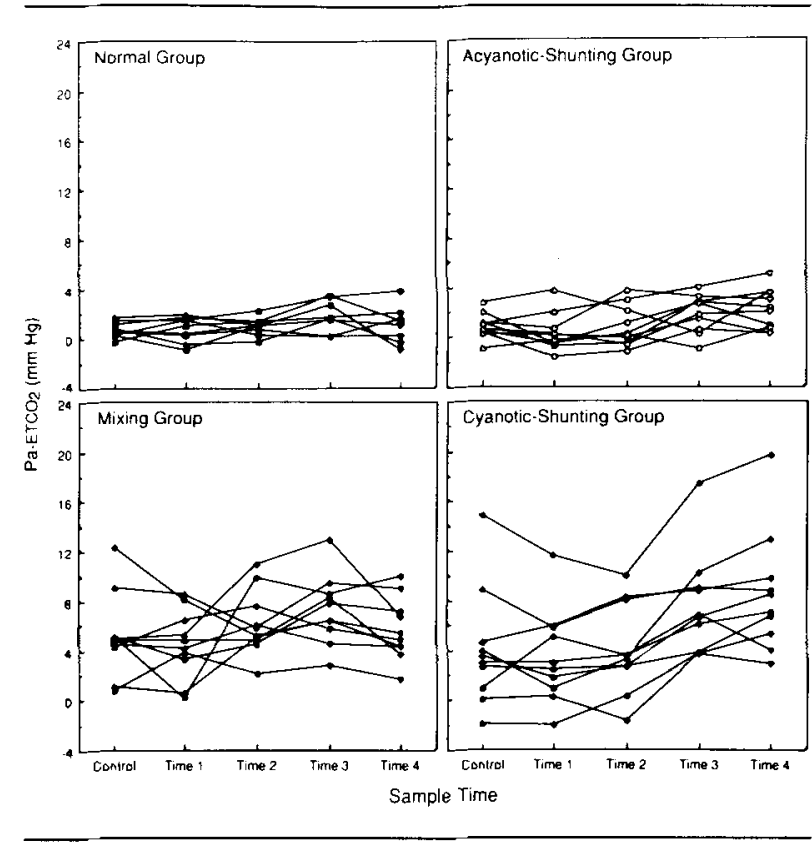

FIGURE 1 The individual arterial to end-tidal $\mathrm{PCO}_{2}$ gradiants $\left(\mathrm{Pa}-\mathrm{ETCO}_{2}\right)$ at the five sampling times in the normal, acyanoticshunting, mixing, and cyanotic-shunting groups of patients. In both the mixing and cyanotic-shunting groups, five of ten patients demonstrated clinically important elevations of the $\mathrm{Pa}-\mathrm{ETCO}_{2}$ at either time 3 or 4 .

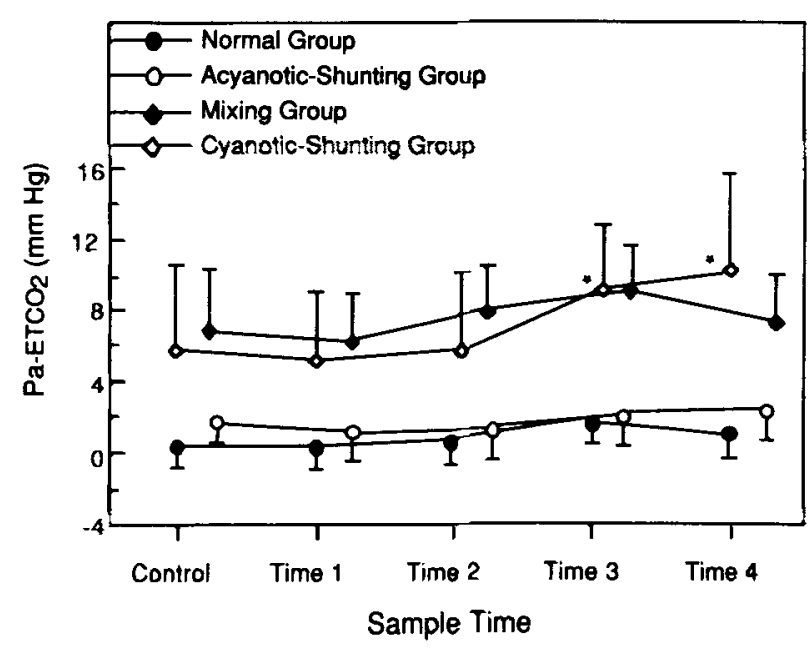

FIGURE 2 The mean ( $\pm \mathrm{SD}$ ) of the $\mathrm{Pa}-\mathrm{ETCO}_{2}$ in the four groups. The $\mathrm{Pa}-\mathrm{ETCO}_{2}$ in the cyanotic patients is greater than in the acyanotic patients. There no statistically significant difference from the control $\mathrm{Pa}-\mathrm{ETCO}_{2}$ in the normal, acyanotic-shunting, or mixing groups of patients, but in the cyanotic-shunting group, the $\mathrm{Pa}-\mathrm{ETCO}_{2}$ calculated at times 3 and 4 were significantly greater than the values at control, time 1 , and time 2 . 


\section{Discussion}

We have shown that, during anaesthesia and surgery, $\mathrm{Pa}-\mathrm{ETCO}_{2}$ remains constant in patients with acyanotic and cyanotic CHD and a stable PBF, but not in patients with cyanotic $C H D$, a variable $P B F$, and the capability of shunting blood from right-to-left. This finding is unexpected since all patients underwent thoracic surgery involving a median sternotomy with retraction of the intrathoracic structures and many had intracardiac communications that would be expected to influence PBF, ventilation/perfusion ratio ( $\dot{\mathrm{V}} / \dot{\mathrm{Q}})$, physiological dead space, and ultimately the $\mathrm{Pa}-\mathrm{ETCO}_{2}$. Previous studies of $\mathrm{Pa}-\mathrm{ETCO}_{2}$ in children with $\mathrm{CHD}^{3,8,13}$ have been completed at a single time during stable haemodynamic conditions and minimal surgical stimulation. Our study differs from other studies in the cohort of patients studied, the duration of the study, the spectrum of surgical stimulation, and the comparison of the data with a control value for $\mathrm{Pa}-\mathrm{ETCO}_{2}$.

The magnitude of the $\mathrm{Pa}-\mathrm{ETCO}_{2}$ in any patient may be attributed to three factors: (1) shunting blood from the venous to arterial side of the circulation, (2) variable ventilation-to-perfusion $\left(\dot{\mathrm{V}}_{\mathrm{A}} / \mathrm{Q}\right)$ ratio throughout the lung (alveolar dead space), and (3) diffusion limitations. ${ }^{10}$ The shunt component of the $\mathrm{Pa}-\mathrm{ETCO}_{2}$ is quantitively less important than the $\dot{\mathrm{V}}_{\mathbf{A}} / \dot{\mathrm{Q}}$ ratio in normal patients because of the relatively small difference between mixed venous and arterial $\mathrm{PCO}_{2}$. The shunt component does become important when the shunt is large, as occurs in many forms of cyanotic congenital heart disease. ${ }^{3,9,11}$ The diffusion factor for $\mathrm{CO}_{2}$ is probably unimportant since $\mathrm{CO}_{2}$ is relatively soluble in body fluids. ${ }^{11}$ The greater $\mathrm{Pa}-\mathrm{ETCO}_{2}$ in cyanotic patients is most likely attributed to the combined effect of the larger alveolar dead space and larger venous admixture. ${ }^{3,9}$

Calculation of the Pa-ETCO ${ }_{2}$ depends upon the accuracy of the measurement of $\mathrm{PETCO}_{2}$. In this study, we sampled $\mathrm{PETCO}_{2}$ from the distal end of the tracheal tube, as recommended previously for the Ayre's t-piece breathing systems. ${ }^{1}$ Distal PetCO ${ }_{2}$ samples estimate the true alveolar $\mathrm{PCO}_{2}$ more accurately than do proximal $\mathrm{PETCO}_{2}$ samples for infants and children less than $12 \mathrm{~kg}$ in body weight.

A gradual increase in $\mathrm{Pa}-\mathrm{ETCO}_{2}$ with time has been demonstrated in adults undergoing coronary artery surgery. ${ }^{12}$ Although this may have been a factor in our study, we believe its effect was small for two reasons: (1) the time interval from induction of anaesthesia to the last sample was only $43 \pm 18 \mathrm{~min}$ and was not different among the four groups of patients: and (2) the Pa-ETCO for the normal or acyanotic groups did not increase during the study period. Our contention is supported by more recent studies, ${ }^{5,13-15}$ that have been unable to demonstrate a time-dependent increase in $\mathrm{Pa}-\mathrm{ETCO}_{2}$.

Children with normal pulmonary circulation (normal group) and those with left-to-right intracardiac shunting and increased PBF (acyanotic-shunting group) had a small Pa-ETCO 2 , since the alveolar dead space is usually normal and they have excellent gas exchange. ${ }^{3,9}$ Several of our acyanotic patients demonstrated a negative $\mathrm{Pa}$ $\mathrm{ETCO}_{2}$ (Table, Figure 1). This was not unexpected: $\mathrm{PaCO}_{2}$ represents an average value of all capillary $\mathrm{PCO}_{2}$ tensions $\left(\mathrm{PcCO}_{2}\right)$; and since $\mathrm{PcCO}_{2}$ is greatest in regions of low $\dot{V} / \dot{Q}$, the alveoli of which empty last at end expiration, $\mathrm{PETCO}_{2}$ may exceed $\mathrm{PaCO}_{2} .{ }^{16}$

The control Pa-ETCO $\mathrm{CO}_{2}$ values for cyanotic patients in our study were greater than those for acyanotic patients (Table, Figure 2). ${ }^{3,6,8,9}$ In cyanotic children, systemic venous blood mixes with pulmonary venous blood, which increases $\mathrm{PaCO}_{2}$ above end-capillary $\mathrm{PCO}_{2}\left(\mathrm{PcCO}_{2}\right)$ levels. ${ }^{3,9}$ Cyanotic children demonstrate an increase in measured physiological and alveolar dead space. ${ }^{9}$ In children with mixing type lesions such as univentricular hearts, this increase in dead space is apparent rather than real: it does not represent ventilation of underperfused pulmonary regions, but is a consequence of the dead space calculations in the presence of inefficient gas exchange. PBF is usually normal or increased in these individuals, ${ }^{9,16}$ which results in a statistically stable $\mathrm{Pa}-\mathrm{ETCO}_{2}$ intraoperatively, although we observed clinically relevant individual changes (Figure 1). The five patients who demonstrated clinically relevant changes in the $\mathrm{Pa}-\mathrm{ETCO}_{2}$ consisted of four patients with a diagnosis of doubleoutlet right ventricle and one patient diagnosed with a transposition of the great arteries with a ventricular septal defect (Table). Although classically considered mixing type lesions, both of these defects enable some separation of pulmonary from systemic circulations (unlike the univentricular heart defects), and as such, intraoperative manipulations may affect PBF. However, pulmonary hypoperfusion is a feature of certain cyanotic congenital cardiac lesions such as tetralogy of Fallot. In such lesions, ventilation of poorly perfused lung regions exists and any change in PBF will result in an increase or decrease in the $\mathrm{Pa}-\mathrm{ETCO}_{2}{ }^{6,17}$

In our study, sternotomy (at time 2) produced neither a statistically nor clinically relevant increase in the $\mathrm{Pa}-\mathrm{ETCO}_{2}$. Studies of adults ${ }^{15,18}$ undergoing coronaryartery bypass grafting and acyanotic children ${ }^{13,19}$ undergoing repair of atrial and ventricular septal defects demonstrated similar results.

Retraction and manipulation of the lungs, which occurred during sample times 2 to 4 , did not affect the $\mathrm{Pa}-\mathrm{ETCO}_{2}$ in the normal or in the acyanotic-shunting 
groups of patients in this study. Several of the cyanotic patients demonstrated increased $\mathrm{Pa}-\mathrm{ETCO}_{2}$ from the measurements taken at sample times 3 and 4. Usually, opening the pleura causes a preferential reduction in the volume of the upper regions of the lung, which increases the alveolar dead space and decreases the airway deadspace, resulting in an unchanged physiological dead space. ${ }^{20}$ These changes increase the $\mathrm{Pa}-\mathrm{ETCO}_{2}$ and only minimally reduce the $\mathrm{PaO}_{2}$. However, if the retraction and manipulation diverts both perfusion and ventilation from the compressed parts of the lung, gas exchange and the $\mathrm{Pa}-\mathrm{ETCO}_{2}$ many not be affected to any degree unless intracardiac right-to-left shunting is induced. ${ }^{21}$ This is likely what occurred in our study.

The stability of the Pa-ETCO ${ }_{2}$ does not imply that the efficiency of $\mathrm{CO}_{2}$ elimination is unchanged. Recent work ${ }^{19}$ has demonstrated that a stable $\mathrm{Pa}-\mathrm{ETCO}_{2}$ may be the result of offsetting changes in both airway and alveolar deadspaces.

Changes in PBF associated with an exacerbation of right-to-left shunting can lead to a redistribution of ventilation relative to perfusion in patients with pulmonary hypoperfusion who are susceptible to alterations in intracardiac right-to-left shunting of blood. This will alter the physiological dead space, venous admixture, and Pa-ETCO ${ }_{2} .6,9,11$ In our study, many of the patients who had tetralogy of Fallot demonstrated supravalvular, valvular, or subvalvular pulmonary stenosis and dynamic pulmonary outflow tract obstruction in combination with a ventricular septal defect. This combination of lesions will frequently cause a variable PBF and right-to-left shunting across the ventricular septal defect, affecting the alveolar component of the physiological dead space and resulting in a more variable $\mathrm{Pa}-\mathrm{ETCO}_{2}{ }^{6,14}$ The anatomy of the other patients in the mixing group also enabled variability in the PBF and the Pa-ETCO ${ }_{2}$.

In conclusion, the use of $\mathrm{PETCO}_{2}$ monitoring to estimate $\mathrm{PaCO}_{2}$ during surgery in acyanotic children with CHD is an acceptable practice since the $\mathrm{Pa}-\mathrm{ETCO}_{2}$ is small and relatively independent of time or surgical stimulation. In children with cyanotic CHD, the use of $\mathrm{PeTCO}_{2}$ intraoperative monitoring is less reliable since the $\mathrm{Pa}-\mathrm{ETCO}_{2}$ is frequently large and is variable during surgical stimulation.

\section{Acknowledgements}

The authors wish to thank Drs. A. C. Bryan and H. O'Brodovich for their critical review of the manuscript. This paper was prepared with the assistance of Medical Publications, The Hospital for Sick Children, Toronto, Ontario.

\section{References}

1 Badgwell JM, Mcleod ME, Lerman J, Creighton $R E$. End-tidal $\mathrm{PCO}_{2}$ measurements sampled at the distal and proximal ends of the endotracheal tube in infants and children. Anesth Analg 1987; 66: 959-64.

2 Bissonnette $B$, Lerman $J$. Single breath end-tidal $\mathrm{CO}_{2}$ estimate of arterial $\mathrm{PCO}_{2}$ in infants and children. Can J Anaesth $1989 ; 36: 110-2$.

3 Burrows FA. Physiologic dead space, venous admixture, and the arterial to end-tidal carbon dioxide difference in infants and children undergoing cardiac surgery. Anesthesiology 1989; 70: 219-25.

4 Nunn JF, Hill $D W$. Respiratory dead space and arterial to end-tidal $\mathrm{CO}_{2}$ tension difference in anesthetized man. $\mathrm{J}$ Appl Physiol 1960; 15: 383-9.

5 Raemer DB, Francis D, Philip JH, Gabel RA. Variation in $\mathrm{PCO}_{2}$ between arterial blood and peak expired gas during anesthesia. Anesth Analg 1983; 62: 1065-9.

6 Schuller $J L$, Bovill TG, Nijveld A. End-tidal carbon dioxide concentration as an indicator of pulmonary blood flow during closed heart surgery in children. A report of two cases. Br J Anaesth 1985; 57: 1257-9.

7 Lindahl SGE, Yates AP, Hatch DJ. Relationship between invasive and noninvasive measurements of gas exchange in anesthetized infants and children. Anesthesiology $1987 ; 66: 168-75$.

8 Fletcher $R$. Invasive and noninvasive measurement of the respiratory deadspace in anesthetized children with cardiac disease. Anesth Analg 1988; 67: 442-7.

9 Fletcher $R$. Relationship between alveolar deadspace and arterial oxygenation in children with congenital cardiac disease. Br J Anaesth 1989; 62: 168-76.

10 Whipp BJ, Wasserman $K$. Alveolar-arterial gas tension differences during graded exercise. J Appl Physiol 1969; 27: 361-5.

11 Farhi $L E$. Ventilation-perfusion relationship and its role in alveolar gas exchange. In: Caro CG (Ed.). Advances in Respiratory Physiology. London: Arnold, 1966; 148-97.

12 Askrog VF, Pender JW, Eckenhoff JE. Changes in physiological dead space during deliberate hypotension.

Anesthesiology 1964; 25: 744-51.

13 Fletcher $R$, Jögi $P$. Increased alveolar deadspace after closure of cardiac septal defects: pulmonary air embolism or failure of homeostasis? Clin Physiol 1986; 6: 423-30.

14 Heneghan CPH, Scallan MJH, Branthwaite MA. Endtidal carbon dioxide during thoracotomy. Its relation to blood level in adults and children. Anaesthesia 1981; 36: 1017-21.

15 Fletcher $R$, Veintemilla $F$. Changes in the arterial to end-tidal $\mathrm{PCO}_{2}$ differences during coronary artery bypass grafting. Acta Anaesthesiol Scand 1989; 33: 656-9. 
16 Fletcher $R$. The arterial-end-tidal $\mathrm{CO}_{2}$ difference during cardiothoracic surgery. Journal of Cardiothoracic Anesthesia 1990; 4: 105-17.

17 Yates $A P B$. Pulmonary blood flow during closed heart surgery. Br J Anaesth 1988; 60: 768-72.

18 Fletcher $R$, Malmkvist $G$, Niklason L, Jonson B. On-line measurement of gas-exchange during cardiac surgery. Acta Anaesthesiol Scand 1986; 30: 295-9.

19 Fletcher $R$, Niklason $L$, Drefeldt $B$. Gas exchange during controlled ventilation in children with normal and abnormal pulmonary circulation: a study using the single breath test for carbon dioxide. Anesth Analg 1986; 65: 645-52.

20 Fletcher $R$. Gas exchange during thoracotomy in children. A study using the single-breath test for $\mathrm{CO}_{2}$. Acta Anaesthesiol Scand 1987; 31: 391-6.

21 Larsson A, Jonmarker $C$, Jögi $P$, Werner $O$. Ventilatory consequences of the lateral position and thoracotomy in children. Can J Anaesth 1987; 34: 141-5. 